11. Graber C, von Boehmer H, Look AT. Notch 1 activation in the molecular pathogenesis of T-cell acute lymphoblastic leukaemia. Nat Cancer Rev 2006;6:347-359.

12. Grego-Bessa J, Diez J, Timmerman L, et al. Notch and epithelial-mesenchyme transition in development and tumor progression: Another turn of the screw. Cell cycle 2004;3:718721.

13. McDaniel R, Wharten DM, Sanchez-Lara PA, et al. NOTCH2 mutations cause Alagille syndrome, a heterogeneous disorder of the notch signaling pathway. Am J Hum Genet 2006;79:169-173.
14. Grundy PE, Breslow NE, Li S, et al. Loss of heterozygosity for chromosomes $1 \mathrm{p}$ and $16 \mathrm{q}$ is an adverse prognostic factor in favorable-histology Wilms tumor: A report from the National Wilms Tumor Study Group. J Clin Oncol 2005;23:7312-7321.

15. Natrajan R, Williams RD, Hing SN, et al. Array CGH profiling of favourable histology Wilms tumours reveals novel gains and losses associated with relapse. J Pathol 2006;210:49-58.

16. Altura RA, Valentine $\mathrm{M}, \mathrm{Li} \mathrm{H}$, et al. Identification of novel regions of deletion in familial Wilms' tumor by comparative genomic hybridization. Cancer Res 1996;56:3837-3841.

\title{
The Absence of Donor-Derived IL-13 Exacerbates the Severity of Acute Graft-Versus-Host Disease Following Allogeneic Bone Marrow Transplantation
}

\author{
Gerhard C. Hildebrandt, MD, ${ }^{1,2 *}$ Sung W. Choi, MD, ${ }^{2}$ Gunnar Mueller, ${ }^{1}$ Krystyna M. Olkiewicz, $\mathrm{MS}^{2}$ \\ Bethany B. Moore, $\mathrm{PhD}^{3}$ and Kenneth R. Cooke, $\mathrm{MD}^{2}$
}

\begin{abstract}
Acute graft versus host disease (aGVHD) after allogeneic bone marrow transplantation (allo-BMT) predominantly involves a Th1type cytokine response. Interestingly, the Th2-cytokine, Interleukin13 (IL-13), produced by alloreactive donor T cells in vitro was recently shown to correlate with clinical aGVHD severity. Using an established mouse model, we show that the systemic cytokine milieu following allo-BMT with IL-13-/- donors is characterized by decreases in serum Th2 cytokines and an increase in serum TNF $\alpha$,
\end{abstract}

Key words: $\quad$ tumor necrosis factor $\alpha$; acute GVHD; T cell; cytokines; IL-13

\section{INTRODUCTION}

Allogeneic (allo-) bone marrow transplantation (BMT) is the only curative option for a number of malignant and non-malignant diseases. The utility of allo-BMT is limited by the development of acute graft versus host disease (aGVHD) [1]. Experimental and clinical data suggest that aGVHD is predominantly mediated by a Th1-type cytokine response [2,3], although an additive role for Th1 and Th 2 cells has been described [4]. Interestingly, the production of Interleukin-13 (IL-13) by donor T cells responding to host antigens in vitro was recently shown to correlate with the severity of clinical aGVHD [5]. IL-13 is a typical Th2-type cytokine that is produced by a wide variety of cells including T cells $[6,7]$. IL-13 binds to its functional receptor (IL-13R) that consists of the IL-4R $\alpha$ chain and the IL-13R $\alpha 1$ chain [8] or to a decoy receptor, called IL-13R $\alpha 2$ [9]. IL-13 exhibits a range of biologic activities, some of which overlap with those observed with IL-4 [10-12]. Although T lymphocytes are a significant producer of IL-13, these cells do not express the IL$13 \mathrm{R}$ on their surface and therefore do not respond to this cytokine [13]. We used a well-established murine BMT model (BALB/cB6) and mice deficient in IL-13 as BMT donors to more clearly determine the role of donor T cell derived IL-13 in the pathogenesis of aGVHD.

\section{MATERIAL AND METHODS}

\section{Mice and Bone Marrow Transplantation}

Female BALB/c IL-13 ${ }^{+/+}\left(\mathrm{H}-2^{\mathrm{d}}\right)$ and C57BL/6 $\left(\mathrm{H}-2^{\mathrm{b}}\right)$ mice were purchased from Jackson Laboratories (Bar Harbor, ME). BALB/c IL-13 ${ }^{-1-}\left(\mathrm{H}-2^{\mathrm{d}}\right)$ mice were provided by Andrew McKenzie [14]. Animals were housed and fed as previously described [15]. and ultimately correlates with higher aGVHD mortality compared to allogeneic controls. In vitro studies further demonstrate that both exogenous and T cell-derived IL-13 can regulate TNF $\alpha$ production by macrophages following lipopolysaccharide stimulation. Thus, donor-derived IL-13 may have a role in modulating inflammatory cytokine release that is associated with aGVHD. Pediatr Blood Cancer 2008;50:911-914. (c) 2007 Wiley-Liss, Inc.
Mice received BMT as described previously [16]. C57BL/6 mice received 13 Gy total body irradiation (TBI; ${ }^{137} \mathrm{Cs}$ source) split into two doses followed by intravenous injection of $5 \times 10^{6}$ bone marrow (BM) and $2 \times 10^{6} \mathrm{CD} 4+$ and $\mathrm{CD} 8+$ magnetic-bead-purified (Miltenyi Biotec GmbH, Bergisch Gladbach, Germany) splenic $\mathrm{T}$ cells from either syngeneic B6, allogeneic BALB/c IL-13 ${ }^{+/+}$or allogeneic BALB/c IL-13 ${ }^{-1-}$ donors. Survival was monitored daily until day 180 .

\section{Fluorescence-activated Cell Sorting (FACS) Analysis}

Cells were analyzed by FACS using fluorescein isothiocyanateconjugated monoclonal antibodies to CD8 and phycoerythrinconjugated antibodies to CD4 (BD Pharmingen, San Diego, CA) as described [15].

This article contains Supplementary Material available at http://www. interscience.wiley.com/jpages/1545-5009/suppmat.

${ }^{1}$ Department of Hematology and Oncology, University of Regensburg Medical School, D-93053 Regensburg, Germany; ${ }^{2}$ Department of Pediatrics, Division of Hematology and Oncology, Bone Marrow Transplantation Program, University of Michigan, Ann Arbor, 48109, Michigan; ${ }^{3}$ Department of Internal Medicine, Division of Pulmonary and Critical Care Medicine, University of Michigan, Ann Arbor, 48109, Michigan

*Correspondence to: Gerhard C. Hildebrandt, Department of Hematology and Oncology, University of Regensburg Medical School, Franz-Josef-Strauß Allee 11, D-93053 Regensburg, Germany. E-mail: gerhard.hildebrandt@klinik.uni-regensburg.de

Received 8 November 2006; Accepted 28 February 2007 
a

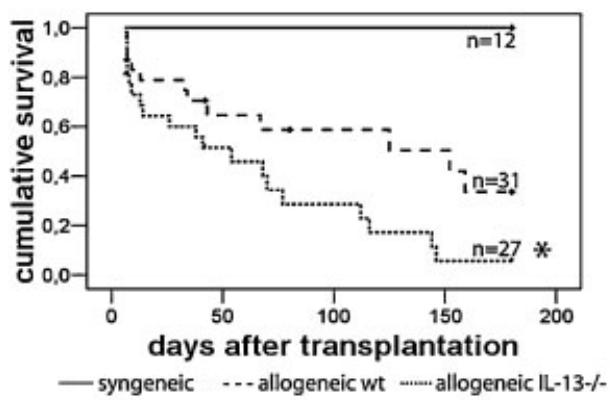

c TNF alpha production

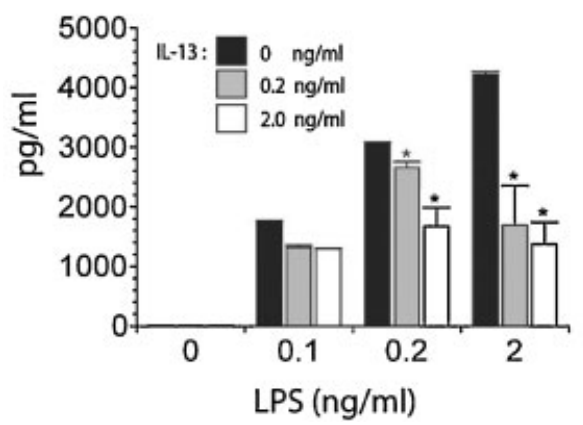

b serum TNF alpha

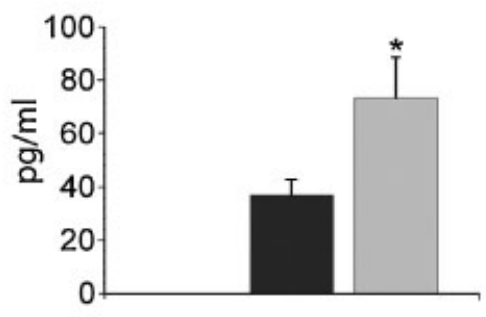

\section{d TNF alpha production}

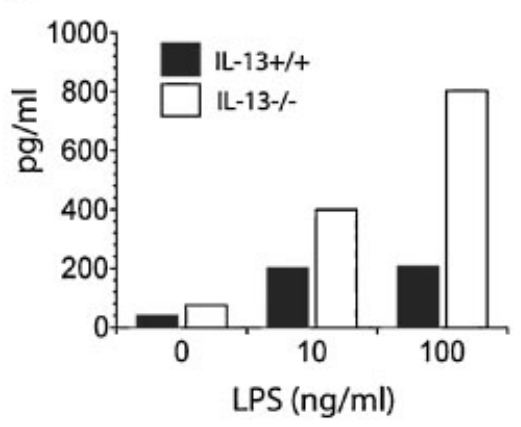

Fig. 1. IL-13 production regulates mortality after allogeneic BMT and TNF $\alpha$ production in vivo and in vitro. Lethally irradiated C57BL/6 mice were transplanted from either syngeneic C57BL/6 ( $\square ;--)$, allogeneic BALB/c IL-13+/+ ( $\mathbf{\square} ;---)$ or allogeneic BALB/c IL-13-/- ( $\square ; \cdots)$ donors as described in Materials and Methods. a: Allogeneic BMT from IL-13-/- donors resulted in significantly increased GVHD-related mortality compared to animals receiving allogeneic IL-13+/+ donor cells. Data presented are combined from four experiments; $\mathrm{n}=12-31$ per group; each experiment concurrently included animals of all groups; $P<0.02$. b: Compared to animals receiving allogeneic IL-13+/+BMT, serum TNF $\alpha$ levels in recipients of allogeneic IL-13-/ - cells were significantly elevated on day 7 (and on day 14; data not shown) after BMT. Data are presented as mean \pm standard error and are combined from three experiments; $\mathrm{n}=9-15$ per group; $P<0.05$. c: Pre-incubation of peritoneal cells with recombinant IL-13 reduces TNF $\alpha$ production following LPS stimulation. Data are presented as mean \pm standard error. $\mathbf{d}$ : TNF $\alpha$ production of peritoneal cells to LPS stimulation is reduced following pre-incubation with supernatant obtained from MLRs using IL-13 $+/+$ T cells + allogeneic APCs compared to pre-incubation with conditioned media obtained using IL-13-/ - T cells + allogeneic APCs. In each case, TNF $\alpha$ measurements were normalized to those obtained when peritoneal cells were pre-incubated with supernatants collected following MLRs with IL-13+/+ T cells or IL-13-/- T cells + media alone. Data are from one of two similar experiments.

\section{T Cell Proliferation}

Donor $\mathrm{T}$ cell expansion in the spleen was assessed in vivo 7 and 14 days following BMT as described [15]. Antigen-specific T cell proliferation in vitro was assessed in mixed lymphocyte reactions (MLR) [15]. C57BL/6, BALB/c IL-13 $3^{+/+}$or BALB/c IL-13 $3^{-/-} \mathrm{T}$ cells were plated at a concentration of $2 \times 10^{5}$ cells/well with $2 \times 10^{4}$ C57BL/6 splenic DCs isolated as described [15]. At $96 \mathrm{hr}$, supernatants were collected for cytokine analysis, responder cells were pulsed with ${ }^{3}[\mathrm{H}]$ thymidine and proliferation was determined $24 \mathrm{hr}$ later on a 1205 Betaplate reader (Packard, Downers, Grove, IL). As a positive control, $\mathrm{T}$ cell proliferation in response to Concavalin A was also determined [15]. In some experiments, C57BL/6 peritoneal cells were pre-incubated with recombinant IL-13 (6 hr) or MLR supernatants (4 hr) prior to stimulation with lipopolysaccharide (LPS) to produce TNF $\alpha$.

\section{Measurement of Cytokine Protein Levels by ELISA}

Concentrations of IFN $\gamma$, IL-13 in serum (day +7 after BMT) and/or cell culture supernatants were measured in duplicate by
ELISA (IFN $\gamma$ : OptEIA; BD Pharmingen. IL-13: Biosource; Camarillo, CA). Serum levels of TNF $\alpha$, IL-2,-4,-5 were determined by Cytokine Bead Array (Th1/Th2 cytokine kit, BD Pharmingen). Assay methods and limits of detection were followed as per the specific protocol.

\section{Statistical Analysis}

Values are expressed as the mean \pm S.E.M. Statistical comparisons between groups were completed using the parametric independent sample $t$-test. Survival curves were plotted using Kaplan-Meier estimates. The log-rank test was used to analyze survival data.

\section{RESULTS AND DISCUSSION}

We investigated the role of IL-13 produced by donor cells in the pathogenesis of aGVHD. First, we determined whether the absence of IL-13 in $\mathrm{T}$ lymphocytes alters alloantigen-specific responses in vitro. $\mathrm{C} 57 \mathrm{BL} / 6, \mathrm{BALB} / \mathrm{c} \mathrm{IL}-13^{+/+}$and $\mathrm{BALB} / \mathrm{c} \mathrm{IL}-13^{-/-} \mathrm{T}$ cells 
were stimulated with B6 splenic DCs. BALB/c IL-13 ${ }^{+/+}$and IL-13 ${ }^{-l-} \mathrm{T}$ cells proliferated comparably well in response to B6 alloantigens compared to syngeneic controls (Supplemental Figure 1a) and only modest changes in IFN $\gamma(P<0.05)$ and IL-2 (n.s.) production were seen in vitro but not in vivo between allogeneic groups (Supplemental Figure 1b and c). While allogeneic wild-type $\mathrm{T}$ cells produced significant amounts of IL-13 in culture, IL-13 levels in MLRs using allogeneic IL-13 ${ }^{-1-}$ T cells were low and did not differ from syngeneic controls (Supplemental Figure 1d). Further, IL-5 (Supplemental Figure 1e) and IL-4 (not shown) production by $\mathrm{IL}-13^{-1-} \mathrm{T}$ cells were also significantly reduced, indicating a general decrease in Th2 cytokine production. Consistent with previous reports [14], similar results were obtained after nonspecific T cell stimulation with Con A (Supplemental Figure 1a-e).

We next determined the effects of IL-13 deficiency in donor cells on splenic $\mathrm{T}$ cell expansion and the resultant proinflammatory cytokine milieu characteristically observed following allo-BMT. Lethally irradiated B6 mice received BMT from either syngeneic (B6) or allogeneic (Balb/c IL-13 $3^{+/+}$or Balb/c IL-13 ${ }^{-l-}$ ) donors. Compared to syngeneic controls, T cells from allogeneic IL-13 ${ }^{+/+}$and IL-13 $3^{-/-}$expanded significantly and equally in the spleen following BMT (Supplemental Figure 2a). Serum levels of IFN $\gamma$, IL-2, IL-5 and IL-13 were all elevated in mice 7 days after allo-BMT from IL- $13^{+/+}$donors compared to syngeneic controls. Concentrations of IL-13 and IL-5, but not IFN $\gamma$ or IL- 2 were significantly reduced following IL-13 ${ }^{-/-}$BMT compared to levels measured in allogeneic IL-13 ${ }^{+/+}$controls (Supplemental Figure 2b-e). Serum IL-4 levels were not detectable in any group.

Th2 cytokine responses have been shown to abrogate the intensity of aGVHD in vivo [17]. We hypothesized that the reduction in Th2 cytokine production following IL-13 ${ }^{-1-}$ BMT would correlate with increased aGVHD severity. As shown in Figure $1 \mathrm{a}, 90 \%$ of recipients of allo-BMT from $\mathrm{IL}-13^{-/-}$donors died of aGVHD by day 150 . By contrast, animals receiving alloBMT from IL-13 ${ }^{+/+}$donors showed a significant reduction in aGVHD mortality $(P<0.02)$. Mortality was associated with increased serum $\mathrm{TNF} \alpha$ levels after allo-BMT, and $\mathrm{TNF} \alpha$ levels were significantly higher after allo-BMT with IL-13-/- cells compared to recipients of allogeneic IL-13 ${ }^{+/+}$BMT (Fig. 1b). We hypothesized that the enhanced mortality seen following alloBMT with $\mathrm{IL}-13^{-1-}$ donors were secondary to the loss of the immunomodulatory effects of IL-13 on macrophage function and $\mathrm{TNF} \alpha$ secretion [18]. To test this, we pre-incubated B6 peritoneal cells prior to LPS stimulation with either recombinant IL-13, or supernatants collected from MLRs using either IL- $13^{+/+}$or IL$13^{-/-} \mathrm{T}$ cells. The latter design was chosen to reproduce in vitro, aspects of immune dysregulation that were occurring in vivo following allo-BMT. As shown in Figure 1c, the addition of recombinant IL-13 to cell culture prior to LPS stimulation resulted in a significant reduction in $\mathrm{TNF} \alpha$ production by peritoneal cells in a dose-dependent fashion. Similar reductions were observed when peritoneal cells were pre-incubated with supernatants collected from MLRs using $\mathrm{T}$ cells capable of producing IL-13 (IL-13 ${ }^{+/+}$) compared to the conditioned media collected from T cells that could not (Fig. 1d). Collectively, these data suggest that donor derived IL-13 down-regulates TNF $\alpha$ production following allo-BMT. This effect in combination with the ability of IL-13 to augment the secretion of Th2 cytokines such as IL-4 or IL-5 or other immunomodulatory proteins like
TGF $\beta$ [19-21] may contribute to a protective role of IL-13 in aGVHD pathophysiology. The previously described correlation between the in vitro production of IL-13 by donor T cells and clinical aGVHD [5] offers an interesting approach to predict GVHD pre-transplant. However, since alloreactive $\mathrm{T}$ cells are a significant source of IL-13 (Supplemental Figure 1d), this correlation may simply reflect the overall allo-activation status of these cells rather that a direct link between IL-13 and GVHD severity. While our data support this hypothesis, it is possible that IL-13 could directly enhance target organ injury in a Th2mediated manner [4]. Whether proinflammatory effects of IL-13, such as those seen with airway hyperresponsiveness, eosinophilia and fibrosis [19,22,23], play a functional role in chronic GVHD remains to be determined.

\section{ACKNOWLEDGMENT}

The authors would like to thank Andrew N. McKenzie, Medical Research Council Laboratory of Molecular Biology, Cambridge, United Kingdom, for providing the IL-13 deficient mice used in these experiments.

\section{REFERENCES}

1. Ferrara JLM, Deeg HJ. Graft versus host disease. New Engl J Med 1991;324:667-674.

2. Antin JH, Ferrara JLM. Cytokine dysregulation and acute graftversus-host disease. Blood 1992;80:2964-2968.

3. Schmaltz C, Alpdogan O, Muriglan SJ, et al. Donor T cell-derived TNF is required for graft-versus-host disease and graft-versustumor activity after bone marrow transplantation. Blood 2003;101: $2440-2445$.

4. Nikolic B, Lee S, Bronson RT, et al. Th1 and Th2 mediate acute graft-versus-host disease, each with distinct end-organ targets. J Clin Invest 2000;105:1289-1298.

5. Jordan WJ, Brookes PA, Szydlo RM, et al. IL-13 production by donor $\mathrm{T}$ cells is prognostic of acute graft-versus-host disease following unrelated donor stem cell transplantation. Blood 2004; 103:717-724.

6. Minty A, Chalon P, Derocq JM, et al. Interleukin-13 is a new human lymphokine regulating inflammatory and immune responses. Nature 1993;362:248-250.

7. McKenzie AN, Culpepper JA, de Waal Malefyt R, et al. Interleukin 13, a T-cell-derived cytokine that regulates human monocyte and B-cell function. Proc Natl Acad Sci USA 1993;90:3735-3739.

8. Hilton DJ, Zhang JG, Metcalf D, et al. Cloning and characterization of a binding subunit of the interleukin 13 receptor that is also a component of the interleukin 4 receptor. Proc Natl Acad Sci USA 1996;93:497-501

9. Caput D, Laurent P, Kaghad M, et al. Cloning and characterization of a specific interleukin (IL)-13 binding protein structurally related to the IL-5 receptor alpha chain. J Biol Chem 1996;271:1692116926.

10. Welham MJ, Learmonth L, Bone H, et al. Interleukin-13 signal transduction in lymphohemopoietic cells. Similarities and differences in signal transduction with interleukin-4 and insulin. J Biol Chem 1995;270:12286-12296.

11. McKenzie GJ, Fallon PG, Emson CL, et al. Simultaneous disruption of interleukin (IL)-4 and IL-13 defines individual roles in T helper cell type 2-mediated responses. J Exp Med 1999;189: $1565-1572$.

12. Lin JX, Migone TS, Tsang M, et al. The role of shared receptor motifs and common Stat proteins in the generation of cytokine 
pleiotropy and redundancy by IL-2, IL-4, IL-7, IL-13, and IL-15 Immunity 1995;2:331-339.

13. Graber P, Gretener D, Herren S, et al. The distribution of IL-13 receptor alpha 1 expression on $\mathrm{B}$ cells, T cells and monocytes and its regulation by IL-13 and IL-4. Eur J Immunol 1998;28:4286-4298.

14. McKenzie GJ, Emson CL, Bell SE, et al. Impaired development of Th2 cells in IL-13-deficient mice. Immunity 1998;9:423-432.

15. Hildebrandt GC, Corrion LA, Olkiewicz KM, et al. Blockade of CXCR3 receptor:ligand interactions reduces leukocyte recruitment to the lung and the severity of experimental idiopathic pneumonia syndrome. J Immunol 2004;173:2050-2059.

16. Hill GR, Crawford JM, Cooke KR, et al. Total body irradiation and acute graft-versus-host disease: The role of gastrointestinal damage and inflammatory cytokines. Blood 1997;90:3204-3213.

17. Ferrara J, Krenger W. Graft versus host disease: The influence of type 1 and type $2 \mathrm{~T}$ cell cytokines. Transfus Med Rev 1998;12: $1-17$.
18. Lentsch AB, Shanley TP, Sarma V, et al. In vivo suppression of NF-kappa B and preservation of I kappa B alpha by interleukin-10 and interleukin-13. J Clin Invest 1997;100:2443-2448.

19. Lee CG, Homer RJ, Zhu Z, et al. Interleukin-13 induces tissue fibrosis by selectively stimulating and activating transforming growth factor beta(1). J Exp Med 2001;194:809-821.

20. Banovic T, MacDonald KP, Morris ES, et al. TGF-beta in allogeneic stem cell transplantation: friend or foe? Blood 2005; 106:2206-2214.

21. Zeller JC, Panoskaltsis-Mortari A, Murphy WJ, et al. Induction of CD4+ T cell alloantigen-specific hyporesponsiveness by IL-10 and TGF-beta. J Immunol 1999;163:3684-3691.

22. Grunig G, Warnock M, Wakil AE, et al. Requirement for IL-13 independently of IL-4 in experimental asthma. Science 1998;282: 2261-2263.

23. Grunig G, Ford JG, Donaldson DD, et al. Roles of interleukin-13 and interferon-gamma in lung inflammation. Chest 2002;121:88S.

\title{
Identification of A Novel p53 In-Frame Deletion in a Li-Fraumeni-Like Family
}

\author{
Joshua D. Schiffman, MD, ${ }^{1}$ Nicolette Chun, $\mathrm{MS}^{2}{ }^{2}$ Paul G. Fisher, $\mathrm{MD},{ }^{1}$ Gary V. Dahl, $\mathrm{MD},{ }^{1}$ \\ James $\mathrm{M}$. Ford, $\mathrm{MD}^{2}$ and Faye A. Eggerding, $\mathrm{MD}, \mathrm{PhD}^{3}$
}

\begin{abstract}
We describe a 2-year-old female with a completely resected cerebral pilocytic astrocytoma who subsequently developed Bprogenitor acute lymphoblastic leukemia (ALL). Her father and paternal uncle were previously diagnosed with glioblastoma multiforme. Sequence analysis of the patient's p 53 gene revealed a novel germline three base-pair deletion (339_341delCTT) in exon 4, resulting in removal of an evolutionarily conserved phenylalanine
\end{abstract}

amino acid residue at codon 113. The same mutation was found in the patient's two clinically unaffected siblings. The in-frame deletion we describe has not previously been reported and adds to our understanding of the biologic effects of p53 gene mutation in Li-Fraumeni syndrome (LFS). Pediatr Blood Cancer 2008;50: 914-916. (ㄷ) 2007 Wiley-Liss, Inc.

Key words: brain tumors; leukemia; Li-Fraumeni-like syndrome p53 gene

\section{INTRODUCTION}

$\mathrm{Li}$-Fraumeni syndrome (LFS) is a rare familial cancer syndrome originally identified through analysis of rhabdomyosarcoma patients and their families [1]. Classic LFS is characterized by bone or soft tissue sarcoma before age 45 years in an individual with a first degree relative diagnosed with cancer before age 45 , and one additional first or second degree relative diagnosed with cancer at an early age or sarcoma at any age [2-4]. Families that exhibit a clustering of LFS cancers but do not conform to all the features of classic LFS are labeled Li-Fraumeni-like (LFL) families. LFL syndrome is characterized by occurrence of a LFS-related cancer before age 45 years in an individual with two first or second degree relative with LFS-related malignancies [5].

Germline mutations in the p53 tumor suppressor gene located on chromosome $17 \mathrm{p} 13$ have been identified in 70-80\% of LFS families and in $20-40 \%$ of LFL families [2,4,6,7]. Germline and somatic p53 mutations are similar, with the majority missense substitutions resulting in defective transcriptional regulation. Inactivating germline mutations in the p53 gene are highly penetrant and individuals harboring p53 mutations have an elevated risk for multiple primary cancers [8]. Here we report the identification of a novel p53 germline mutation in a child with pilocytic astrocytoma and leukemia, in a LFL family with a clustering of brain tumors.

\section{CLINICAL REPORT}

A previously healthy 2 1/2-year-old presented with a seizure. Brain MRI revealed a left parietal tumor. The tumor was completely resected and found to be a pilocytic astrocytoma (WHO grade I). No adjuvant therapy was necessary.

At age 4 years, she presented with pallor, hepatosplenomegaly, and fever. Peripheral blood white cell count was $21,800 / \mathrm{mm}^{3}$ with $90 \%$ lymphoblasts. Bone marrow aspirate confirmed the diagnosis of B-progenitor cell acute lymphoblastic leukemia (ALL). Cytogenetic analysis identified the TEL/AML-1 fusion gene in lymphoblasts. There was no central nervous system disease. After two years of treatment per Pediatric Oncology Group protocols 9900 and 9904 regimen $\mathrm{D}$, she is now on maintenance chemotherapy.

A family history revealed the death of the patient's father secondary to glioblastoma multiforme at age 46. The patient's paternal uncle died secondary to glioblastoma at age 48. The patient's mother is healthy. The maternal grandmother developed breast cancer at age 60, and died at age 61 from heart failure. A family pedigree is in Figure 1. A diagnosis of LFL syndrome was considered. The mother consented to 553 genotyping for the patient

${ }^{1}$ Division of Pediatric Hematology/Oncology, Stanford University School of Medicine, Stanford, California 94304; ${ }^{2}$ Division of Oncology, Stanford University School of Medicine, Stanford, California 94304; ${ }^{3}$ Huntington Medical Research Institutes, Pasadena, California 91101

*Correspondence to: Joshua D. Schiffman, Division of Pediatric Hematology/Oncology, Stanford University School of Medicine, 1000 Welch Road, Suite 300, Stanford, CA 94304.

E-mail: jschiffman@1pch.org

Received 22 December 2006; Accepted 22 March 2007 